\title{
Non-mnestic Cognitive Function in the Scopolamine Model of Alzheimer's Disease
}

\author{
MARC C. OBONSAWIN ${ }^{1 *}$, ANNE ROBERTSON ${ }^{2}$, JOHN R. CRAWFORD $^{3}$, CHRIS PERERA $^{4}$, \\ SHONA WALKER ${ }^{4}$, LOUISE BLACKMORE ${ }^{5}$, DENIS M. PARKER ${ }^{6}$ and JOHN A. O. BESSON \\ ${ }^{1}$ Department of Psychology, University of Strathclyde, Glasgow, UK \\ ${ }^{2}$ Department of Anaesthesiology, Foresterhill, Aberdeen, UK \\ ${ }^{3}$ Department of Psychology, University of Aberdeen, Aberdeen, UK \\ ${ }^{4}$ Royal Cornhill Hospital, Aberdeen, UK \\ ${ }^{5}$ Department of Clinical Psychology, Inverness, $U K$ \\ ${ }^{6}$ Department of Psychology, Glasgow Caledonian University, Glasgow, UK \\ ${ }^{7}$ Division of Psychiatry, St Thomas' Hospital, London, UK
}

\begin{abstract}
The contribution of cholinergic dysfunction to the non-mnestic cognitive impairments associated with senile dementia of the Alzheimer type (SDAT) was investigated. Scopolamine $(0.5 \mathrm{mg})$ was administered intravenously to 12 healthy individuals, and their performance on selected subtests of the Wechsler Adult Intelligence Scale Revised (WAIS-R), and on additional non-mnestic neuropsychological tests were compared to that of 12 healthy control participants. The results demonstrate that scopolamine does impair performance on components of the WAIS-R, but that the Fuld WAIS-R profile does not have a cholinergic basis. Scopolamine did not impair performance on verbal fluency, the Token Test, Judgment of Line Orientation, finger tapping, the Modified Card Sorting Test, or the Mini-Mental State Examination. The results do not support the hypothesis that the cholinergic system contributes to the non-mnestic impairments in SDAT. C 1998 John Wiley \& Sons, Ltd.
\end{abstract}

KEY WORDS — scopolamine; muscarinic blockade; senile dementia of the Alzheimer's type; Fuld profile

\section{INTRODUCTION}

The extent to which the well-documented changes in the cholinergic system accompanying senile dementia of the Alzheimer type (SDAT) (for reviews see Crawford et al., 1990; Kasa et al., 1997) account for the symptoms of this disease continues to be a matter of debate. One approach to resolve this issue has been to examine the effects of temporary muscarinic receptor blockade on the performance of healthy people on neuropsychological tests sensitive to dementia. According to this approach, if muscarinic receptor blockers like scopolamine mimic the cognitive impairments of SDAT when they are administered to healthy individuals, then the cholinergic dysfunction characteristic of SDAT may be the physiological

*Correspondence to: M. C. Obonsawin, Department of Psychology, University of Strathclyde, 40 George Street, Glasgow G1 1QE, UK. Tel: +44 141 548-2573. Fax: +44 141 548-4001. e-mail: m.c.obonsawin@strath.ac.uk basis for these cognitive impairments. In fact, there is considerable evidence that muscarinic receptor blockers like scopolamine do mimic some aspects of the memory difficulties seen in SDAT (Broks et al., 1988; Caine et al., 1981; Kopelman and Corn, 1988; Obonsawin et al., 1996; Rusted and Warburton, 1988), and these results raise the possibility that the dysfunctional cholinergic system may be responsible for the memory difficulties in SDAT. However, these results are difficult to interpret. Whereas it is possible that cholinergic dysfunction does contribute to the memory problems in dementia, it is not clear that the administration of scopolamine provides a good model for SDAT. Indeed, an important weakness of the scopolamine model of SDAT is that it is difficult to evaluate the result of a scopolamine challenge because the validity of the scopolamine model remains to be established. Nevertheless, the effects of scopolamine on memory tasks have generated considerable research into the physiological basis of the cognitive 
impairments of SDAT, and its effects on other cognitive functions deserve investigation.

The effects of scopolamine on non-mnestic cognitive tasks sensitive to SDAT have received less attention. Many of the relevant investigations have focused on the effects of scopolamine on the performance of tests of language function and of general intellectual ability. Most authors have not reported any effect of scopolamine on the performance of tests of language function, but the range of functions assessed has been narrow. There is some consensus that scopolamine has no effect on object naming (Flicker et al., 1990, 1992; Zemishlany and Thorne, 1991), but there is evidence that scopolamine impairs the performance of young participants on some spelling tests (Aarsland et al., 1994). Performance on tests of verbal fluency is impaired in individuals with SDAT (Christensen et al., 1992; Miller, 1984; Rosen, 1980), but there is less agreement about the effects of scopolamine on verbal fluency. Many authors have reported no effect of scopolamine on verbal fluency (Beatty et al., 1986; Dunne, 1990; Kopelman and Corn, 1988; Zemishlany and Thorne, 1991), some authors have reported that scopolamine decreases performance on verbal fluency (Aarsland et al., 1994; Molchan et al., 1992; Sunderland et al., 1987) and yet other authors have reported that scopolamine improves performance on the verbal fluency task (Dunne, 1993; Lines et al., 1991). It appears that the effects of scopolamine on tests of language function sensitive to SDAT remain unresolved.

The effects of scopolamine on the performance on tests of general intellectual ability have been predominantly investigated with the Wechsler Adult Intelligence Scale, both the original (WAIS) and revised (WAIS-R) versions. Fuld (1984) reported that 53 per cent of participants who had been administered scopolamine showed a characteristic pattern of performance on the subtests of the WAIS. This pattern has come to be called the Fuld profile. Only 18 per cent of the control participants in Fuld's (1984) study showed the profile. There is some evidence that this profile is more likely to occur in people with SDAT but not other forms of dementia (Brinkman and Braun, 1984; Fuld, 1984). These results provided support for the hypothesis that cholinergic dysfunction in SDAT was contributing substantially to the dementia. Many subsequent investigators of the profile have used the revised version of the Scale, the WAIS-R. The rate of occurrence of the profile in both versions of the WAIS is not significantly different (Filley et al., 1987). The evidence appears to indicate that the profile occurs specifically in conditions of cholinergic dysfunction such as SDAT, and occurs rarely in other populations, such as the healthy elderly (Satz et al., 1987, 1990; Tuokko and Crockett, 1987), or individuals suffering from head trauma (Heinrichs and Celinski, 1987), from schizophrenia or affective disorders (Ryan and Paolo, 1989), or from dementia secondary to AIDS (van Gorp et al., 1990).

The potential importance of the Fuld profile is eclipsed by two unresolved issues. The first issue is that until now, there has been no prospective study examining whether the profile does indeed occur in healthy individuals during muscarinic receptor blockade. Fuld's (1984) report consisted only of a retrospective examination of data collected by Drachman and Leavitt (1974). The second issue is the inconsistency with which other investigators have been able to detect the occurrence of the profile in individuals with Alzheimer's disease. Fuld (1984), Brinkman and Braun (1984) and Filley et al. (1987) have all reported that the profile occurs in 45-60 per cent of individuals with SDAT. However, Gfeller and Rankin (1991), Goldman et al. (1992) and Massman and Bigler (1993) have not been able to replicate these results. The occurrence of the profile in Alzheimer's disease is still a matter of debate, and evidence for the cholinergic basis of the profile remains unreplicated.

The aim of the present study was to test the prediction that the performance of healthy individuals after scopolamine administration would be similar to the performance of individuals with SDAT on neuropsychological tests sensitive to a wide range of functions: word generation, auditory verbal comprehension, executive function, and motor performance. The present study is also the first prospective study to examine the claim that the administration of scopolamine gives rise to the Fuld profile on subtests of the WAIS-R. Performance on all the neuropsychological tests chosen is known to be impaired in SDAT.

\section{MATERIALS AND METHODS}

\section{Participants}

Twenty-four healthy participants (Table 1) took part in the study. Participants were only accepted 
Table 1. Summary description of participants

\begin{tabular}{lcc}
\hline & Saline & Scopolamine $(0 \cdot 5 \mathrm{mg})$ \\
\hline$n$ & 12 & 12 \\
Age (mean years $\pm \mathrm{SD})$ & $40 \cdot 83 \pm 12 \cdot 55$ & $43 \cdot 67 \pm 13 \cdot 41$ \\
Age range (years) & $20-63$ & $21-64$ \\
Sex ratio (m:f) & $3: 9$ & $3: 9$ \\
NART score (mean \pm SD) & $35 \cdot 09 \pm 7 \cdot 23$ & $38 \cdot 25 \pm 5 \cdot 82$ \\
Raven's matrices score (mean $\pm \mathrm{SD})$ & $51 \cdot 17 \pm 7 \cdot 81$ & $51.42 \pm 6 \cdot 82$ \\
\hline
\end{tabular}

into the study after undergoing a thorough medical examination and providing signed, informed medical consent. Participants had abstained from alcohol (for $24 \mathrm{~h}$ ) and from coffee and tea (for $12 \mathrm{~h})$ prior to the experimental session. They received an honorarium for their participation. The study was approved by the Joint Ethical Committee of the Grampian Health Board and the University of Aberdeen.

\section{Scopolamine administration}

Twelve of the healthy participants received an intravenous injection of scopolamine $(0.5 \mathrm{mg})$ in saline, and 12 participants were injected with an equal volume of saline. Both groups were matched for age, sex, and intellectual ability, based on their performance on the National Adult Reading Test (Nelson, 1982) and the Standard Progressive Matrices (Raven, 1958) (Table 1). Participants were paired on the basis of these indices, and randomly allocated to one of the two groups by one of the authors not involved in the drug administration procedure (DMP). Group membership was only revealed to the investigator carrying out the injection a few minutes prior to the injection. All tests were administered by MO, who remained blind to the group allocation until testing was completed. The dose was not corrected for body size, as previous work by Safer and Allen (1971) had suggested that such corrections resulted in more variable effects of the drug. Neuropsychological testing began 45 min after scopolamine administration, and continued for approximately $150 \mathrm{~min}$. This time period reflected the period of peak effectiveness of intravenously administered scopolamine, according to evidence presented by Safer and Allan (1971).

\section{Physiological index of central cholinergic blockade}

The change in visual near point was assessed once before injection and at regular fixed intervals

(C) 1998 John Wiley \& Sons, Ltd. during the $5 \mathrm{~h}$ following injection. The change in visual near point has been used previously as an index of muscarinic receptor blockade (Kopelman and Corn, 1988). Its use is based on the fact that $0.6 \mathrm{mg}$ of scopolamine, but not equal doses of atropinergic drugs, induces changes in visual near point (Brown, 1990), and the assumption that the ocular effects of scopolamine must be due to its ability to penetrate the CNS more readily than other antimuscarinic drugs. To measure the visual near point, participants were required to look into a modified lenticular stereoscope. The lenses were removed from the eyepieces, and the original shaft was replaced with a graduated shaft that had been lengthened to extend to $730 \mathrm{~mm}$ from the eyes. A sample of prose was fixed to the stereogram holder, and the holder was moved progressively closer to the subject's eyes by sliding it on the shaft. The subject indicated the point at which the text was out of focus. The final score was the distance of the card (in $\mathrm{cm}$ ) from the eyes when the subject indicated that the text was out of focus.

\section{Neuropsychological tests}

All participants received the following neuropsychological tests to assess a variety of nonmnestic functions.

(1) The Controlled Oral Word Association Test (COWAT), or verbal fluency task, was administered as described by Benton and Hamsher (1976, 1978) and Goodglass and Kaplan (1972) to assess word generation (language and executive functions). The letters F, A and S were used, and participants were asked to generate as many words as possible for each letter. Sixty seconds were allowed for each letter. The score is the total number of words correctly produced over the $3 \mathrm{~min}$ period. Many authors have reported that individuals with SDAT are impaired on this task 
(Christensen et al., 1992; Miller, 1984; Rosen, 1980).

(2) To assess language function, a shortened, 16-item version of the Token Test was administered and scored according to the instructions provided by Spellacy and Spreen (1969). Participants were presented with plastic tokens varying in size, shape and colour. They were then given instructions to carry out different tasks with these tokens. The instructions increased in complexity as the task progressed. The performance of individuals with SDAT is impaired on the Token Test (Emery, 1985; FaberLangendoen et al., 1988; Thompson, 1987).

(3) The Judgment of Line Orientation Test was administered and scored according to Benton et al. (1983) to assess perceptual function. Participants were shown two practice and 30 test items from a test booklet. Each item of the test consists of two components: a stimulus on the top page of the booklet, and an array of 11 possible responses on the bottom page of the booklet. The subject was required to choose two responses from the array on the bottom page that have the same orientation as the two stimulus lines on the top of the page. The performance of individuals with Alzheimer's disease has been reported to be impaired on this task (Eslinger and Benton, 1983; Eslinger et al., 1985; Ska et al., 1990).

(4) The Modified Card Sorting Test is thought to measure the ability to form concepts and the ability to shift cognitive set. Like the COWAT, it is thought to assess the integrity of frontal lobe function (Parker and Crawford, 1992). Participants are required to sort cards according to specific dimensions (colour, number and shape), and to change the sorting rule on a cue provided by the examiner. It was administered and scored according to the method described by Nelson (1976). The performance of individuals with dementia is impaired on this task (Bondi et al., 1993; Hart et al., 1988).

(5) The Finger Tapping task assesses manual dexterity and fine motor control. Participants were required to tap a mechanical counter (Lafayette Instruments Co.). The number of times the counter was tapped in $10 \mathrm{~s}$ was recorded. Administration and scoring was carried out according to the suggestions provided by the manual accompanying the fingertapper. The final score was the average number of taps over five trials. These five trials were selected in one of two ways. If the subject completed five consecutive trials within a fivepoint range, no additional trials were required and the average of these five trials was taken. The maximum number of trials allowed was ten. If there were not five consecutive trials within a five-point range, the final score was the average of the five highest trials. The required number of trials were completed for both the dominant and non-dominant hand. In comparison to the performance of agematched healthy individuals, the performance of individuals with dementia is impaired on this task (Ott et al., 1995).

(6) The cognitive state of the participants was assessed according to the Mini-Mental State Examination (MMSE), as described by Folstein et al. (1975).

(7) In addition, all participants received the seven subtests of the WAIS-R that form part of the Fuld WAIS-R profile: Information, Digit Span, Vocabulary, Similarities, Block Design, Object Assembly and Digit Symbol. The seven subtests were administered according to the instructions provided in Wechsler (1981). Tests were administered in the following order: Information, Block Design, Digit Span, Object Assembly, Vocabulary, Digit Symbol, MiniMental State Examination, Similarities, Finger Tapping (dominant hand), COWAT, Token Test, finger-tapping (non-dominant), Judgment of Line Orientation and MCST.

\section{RESULTS}

\section{Visual near point}

The change in visual near point for both groups is presented in Figure 1. Although there was no significant group effect $(F(1,22)=1 \cdot 76, p=0 \cdot 199)$, there was a significant within-participants effect of time $(F(3,66)=15 \cdot 07, p<0 \cdot 001)$, and a significant interaction between group and time $(F(3,66)=$ $4 \cdot 76, p=0.005)$. The two groups therefore differed in the change in visual near point over the course of the experiment.

\section{WAIS-R subtests and the Fuld profile}

The performance of the participants on the WAIS-R subtests are shown in Table 2. Because we compared the performance of participants on seven subtests with $t$-tests, we applied a Bonferroni 


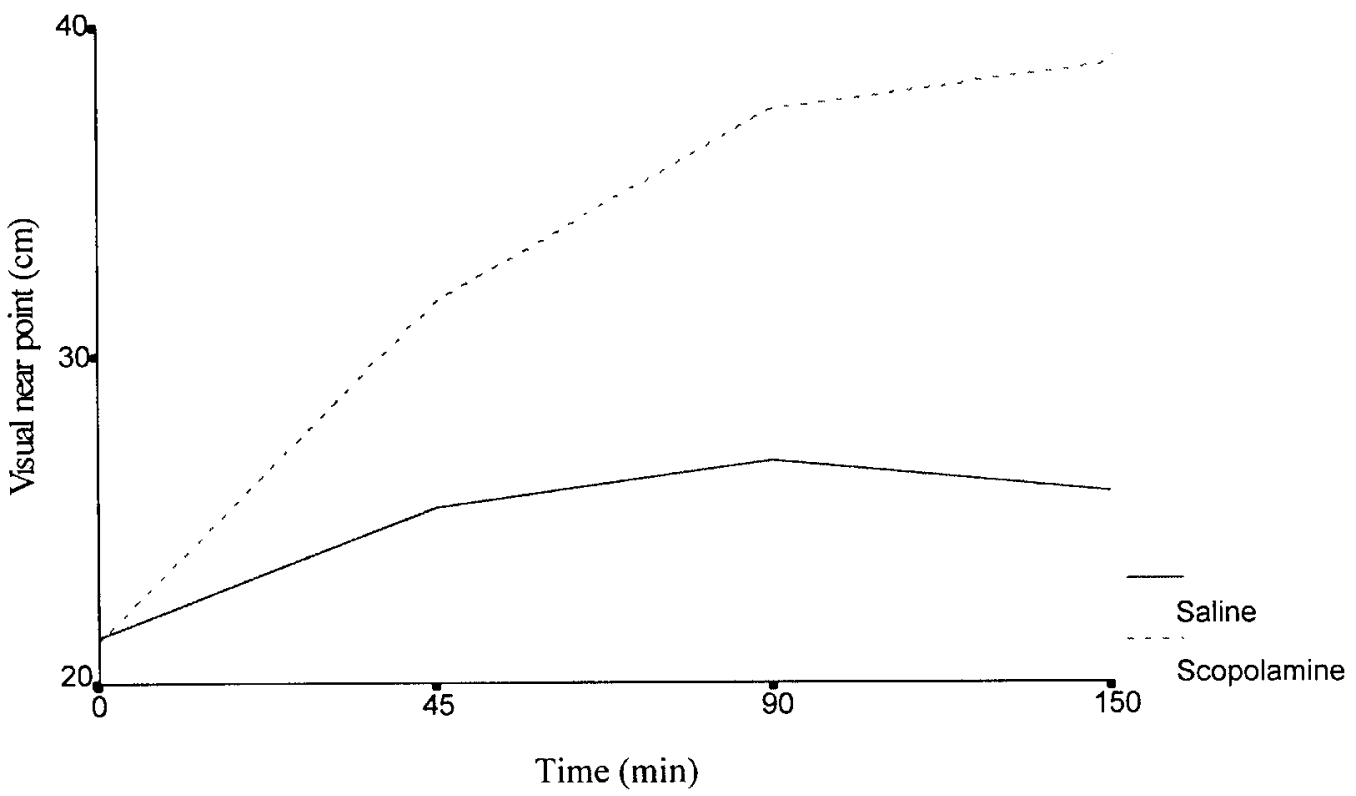

Figure 1. The change in mean visual near point during neuropsychological testing. Time 0 indicates the time of drug (or saline) injection

correction to change the significance level from 0.05 to 0.007 . The performance of the participants in the scopolamine group was lower than that of participants in the control group on only one subtest, Block Design. There was no significant difference between the two groups on any of the other subtests. Only one of the 12 participants in the scopolamine group showed the Fuld profile, and none of the 12 participants in the control group did. This apparent small difference is not statistically significant according to Fisher's Exact Probability $(p=0 \cdot 50)$.

\section{Neuropsychological tests of cognitive function}

The aim of this section was to see if individuals who were administered scopolamine would show a pattern of performance that reflected some aspects of dementia, especially dementia of the type associated with SDAT. The results from the neuropsychological tests are summarised in Table 3. $T$-tests demonstrated no significant differences between the participants in the control group and those receiving scopolamine on the verbal fluency, Judgment of Line Orientation, the Token Test, Finger Tapping or the MMSE. Mann-Whitney $\mathrm{U}$ tests demonstrated no significant differences between the two groups on either of the two indices of the Modified Card Sorting Test.

\section{DISCUSSION}

The aims of the present study were to test the hypothesis that scopolamine impairs the performance of

Table 2. Effect of scopolamine on performance of selected subtests of the WAIS-R (age-corrected scores, mean $\pm \mathrm{SD}$ ). A Bonferroni correction altered the significance level from 0.05 to 0.007

\begin{tabular}{|c|c|c|c|c|}
\hline Subtest & Control $(n=12)$ & Scopolamine $(n=12)$ & $t$ & $p$ \\
\hline Information & $10 \cdot 67 \pm 1.92$ & $11.08 \pm 2 \cdot 50$ & -0.46 & 0.652 \\
\hline Digit Span & $11.75 \pm 1.49$ & $10 \cdot 75 \pm 3 \cdot 50$ & 0.92 & $0 \cdot 368$ \\
\hline Vocabulary & $12.83 \pm 1.99$ & $12.75 \pm 2.70$ & 0.09 & 0.932 \\
\hline Similarities & $11.67 \pm 1.50$ & $11.25 \pm 2.45$ & $0 \cdot 50$ & 0.621 \\
\hline Block Design & $13 \cdot 17 \pm 2 \cdot 37$ & $9 \cdot 83 \pm 2.66$ & $3 \cdot 24$ & 0.004 \\
\hline Object Assembly & $10 \cdot 75 \pm 2 \cdot 14$ & $8.75 \pm 2.38$ & $2 \cdot 17$ & 0.041 \\
\hline Digit Symbol & $11 \cdot 25 \pm 2.70$ & $9.75 \pm 2.09$ & 1.52 & $0 \cdot 143$ \\
\hline
\end{tabular}


Table 3. Effects of scopolamine on performance on tests of neuropsychological function (mean \pm SD)

\begin{tabular}{|c|c|c|c|c|}
\hline Test & Control & Scopolamine & $t / U$ & $p$ \\
\hline Verbal Fluency* & $39 \cdot 08 \pm 6 \cdot 17$ & $46 \cdot 75 \pm 14 \cdot 30$ & -1.71 & $0 \cdot 102$ \\
\hline Judgment of Line Orientation* & $24.92 \pm 2.54$ & $21 \cdot 58 \pm 5 \cdot 38$ & 1.94 & 0.065 \\
\hline Token Test* & $77.75 \pm 0.45$ & $77 \cdot 33 \pm 1 \cdot 15$ & $1 \cdot 16$ & 0.257 \\
\hline \multicolumn{5}{|l|}{ Finger Tapping* } \\
\hline Dominant hand & $42 \cdot 40 \pm 7 \cdot 57$ & $44.88 \pm 4.95$ & $-0 \cdot 95$ & $0 \cdot 352$ \\
\hline Non-dominant hand & $45 \cdot 34 \pm 18 \cdot 34$ & $39 \cdot 17 \pm 4 \cdot 54$ & $1 \cdot 13$ & $0 \cdot 270$ \\
\hline MMSE* & $28 \cdot 67 \pm 1 \cdot 30$ & $27 \cdot 92 \pm 2 \cdot 27$ & 0.99 & 0.332 \\
\hline \multicolumn{5}{|l|}{ Wisconsin Card Sorting Test $\dagger$} \\
\hline Number of categories & $5 \cdot 00 \pm 1.95$ & $4.42 \pm 1.68$ & $49 \cdot 0$ & $0 \cdot 198$ \\
\hline$\%$ perseverative errors & $20 \cdot 34 \pm 30 \cdot 50$ & $25 \cdot 40 \pm 20 \cdot 33$ & $52 \cdot 0$ & 0.266 \\
\hline
\end{tabular}

*The two experimental conditions were compared with a $t$-test.

$\uparrow$ The two experimental conditions were compared with a Mann-Whitney $U$ test.

healthy individuals on non-mnestic neuropsychological tests known to be sensitive to SDAT, and to verify the cholinergic basis of the Fuld profile. The results indicate that (i) the Fuld WAIS or WAIS-R profile is not a marker for impaired function of the central cholinergic system, but performance on individual subtests of the WAIS-R may be affected by scopolamine, and (ii) the performance of healthy participants after administration of scopolamine does not resemble the performance of individuals with SDAT on neuropsychological tests of nonmnestic cognitive function (verbal fluency, the Token Test, Finger Tapping, and the MCST). These results do not support the hypothesis that the physiological basis for the non-mnestic cognitive impairments in SDAT is cholinergic dysfunction.

The origins of the Fuld profile lie in the scopolamine model of SDAT and can be traced to a report by Fuld (1984) who conducted a retrospective examination of the performance on the WAIS of healthy participants who had been administered scopolamine in a previous study (Drachman and Leavitt, 1972, 1974). The present study is the first prospective study to investigate the cholinergic basis of the profile. The results do provide evidence that muscarinic receptor blockade impairs performance on the Block Design subtest of the WAIS-R, but do not provide evidence to substantiate the claim that cholinergic blockade leads to the characteristic profile reported by Fuld (1984).

Previous studies reporting the occurrence of the Fuld profile in individuals with SDAT were conducted with participants up to the ages of 83 (Fuld, 1984), and 86 years (Brinkman and Braun,
1984), despite the fact that norms for the WAIS-R are only available for individuals up to the age of 74. It is not clear in either report if the age of participants who do show the profile is different from the age of participants who do not show the profile, nor is there any explanation in these reports on how the age-corrected scores for the participants over 74 were obtained. In the absence of such information, one can only assume that the subtest scores of participants up to the age of 86 years of age were corrected for age with norms intended for participants between the ages of 70 and 74 years of age. If this is indeed the case, then the reports on the occurrence of the cholinergic WAIS-R profile in dementia may not be reliable. Given the results of the present study, and the use of inappropriate norms to support the existence of the cholinergic WAIS-R profile in SDAT, we do not recommend the use of this profile to investigate the presence of cholinergic dysfunction.

The administration of scopolamine to healthy individuals did not affect performance on any of the other neuropsychological measures. To certify that scopolamine did indeed cause blockade of central muscarinic receptors, we monitored changes in visual near point. Changes in visual near point during cholinergic blockade have been interpreted as reflecting blockade of central muscarinic receptors (Kopelman and Corn, 1988). Our results indicate a progressive increase in central muscarinic receptor blockade during neuropsychological testing, but do not indicate any increase in the occurrence of the Fuld profile, or any impairment of performance on the neuropsychological tasks. 
The lack of effect of scopolamine on the verbal fluency test resemble the results obtained in some previous studies (Beatty et al., 1986; Curran et al., 1991; Dunne, 1990; Kopelman and Corn, 1988; Zemishlany and Thorne, 1991), although there are some reports that scopolamine impairs (Aarsland et al., 1994; Molchan et al., 1992; Sunderland et al., 1987) or even improves performance on the task (Dunne, 1993; Lines et al., 1991). The reasons for these discrepancies remain unclear. Curran et al. (1991) speculate that only higher doses of scopolamine impair performance on verbal fluency. Their speculation is based on the results obtained by Sunderland et al. (1987) in which only the higher dose $(0.5 \mathrm{mg})$ but not the lower doses $(0.1$ and $0.25 \mathrm{mg}$ ) of scopolamine impaired performance on verbal fluency in elderly participants. However, Molchan et al. (1992) reported that $0.5 \mathrm{mg}$ of scopolamine impairs performance on the verbal fluency task in elderly (mean age of 66.5) but not young (mean age of 27) participants. These results raise the possibility that the inconsistent results of past studies may be due in part to differences in the age of the participants.

The only effect of scopolamine appears to be on the Block Design subtest of the WAIS-R, but the scopolamine-induced impairment resembles an age-associated more than a dementia-associated impairment. Previous investigators have commented that scopolamine-induced memory impairments resemble age-associated rather than dementia-associated changes in function (Bartus et al., 1982; Coyle et al., 1983; Drachman and Leavitt, 1974; Flicker et al., 1990). There is considerable evidence for changes in cholinergic function with ageing (Dunnet, 1991; Gallagher and Colombo, 1995; Gottfries, 1990). Decreases in choline uptake, acetylcholine synthesis, choline acetyltransferase activity, transmitter release, muscarinic receptor density, volume and number of cholinergic neurons have all been reported to be associated with ageing in humans and other species (Bowen, 1984; Davies, 1978; Freund, 1980; Gibson and Peterson, 1981; McGeer and McGeer, 1981; Mesulam et al., 1987; Meyer et al., 1984). However, our knowledge of the contribution of the cholinergic system to the changes in cognition accompanying ageing is far from complete.

The results of the present study do not provide any support for the hypothesis that the wellrecognised changes in cholinergic system function in SDAT are contributing to the cognitive impairments in that condition, but two points must be borne in mind when considering these results. Firstly, the range of non-mnestic psychological functions tested in this study was broader than in past studies, but was by no means exhaustive. It is possible that scopolamine does affect the performance on other non-mnestic tests that are also sensitive to SDAT (e.g. Aarsland et al., 1994). Secondly, the scopolamine model may not be an adequate test of this hypothesis. The dissimilarity between the known mechanism of action of scopolamine and the known pathophysiology of SDAT is such that comparisons between scopolamine-induced impairments and impairments associated with dementia must be interpreted with caution. Scopolamine causes cholinergic dysfunction by temporarily blocking muscarinic receptors on all target neurons of the brain, including receptors in the cerebral cortex, amygdala, hippocampus and thalamus, and receptors on the cerebral vasculature. During receptor blockade with scopolamine, the target cells are still functional, but do not receive cholinergic input. In contrast, dysfunction of the cholinergic cells of Ch4 and Ch5 in SDAT is accompanied by the death of target neurons in the cerebral cortex and hippocampus. It is still not clear whether cell loss in the cortex precedes or follows from cell loss in Ch4 (Cullen et al., 1997; Mesulam, 1991). In contrast to temporary muscarinic receptor blockade, cholinergic dysfunction in dementia is progressively degenerative and permanent, affects both muscarinic and nicotinic receptors, and is accompanied by the death of cortical and hippocampal target cells. The importance of the differences between the mechanism of action of scopolamine and the pathophysiology of SDAT is emphasized by the ability of cholinergic agonists like physostigmine and tacrine to reverse or diminish the effects of scopolamine (Ghoneim and Mewaldt, 1977; Kirkby et al., 1996; Mewaldt and Ghoneim, 1979; Murray and Cross, 1991; Riekkinen et al., 1991; Tsukada et al., 1997), but have minimal effects on alleviating the dementia associated with SDAT (Crawford et al., 1992; Eagger et al., 1991; Farlow et al., 1992; Freeman and Dawson, 1991; Sahakian et al., 1993).

Two unresolved issues arise from the scopolamine model of SDAT. The first is the issue of whether the cholinergic system dysfunction associated with SDAT contributes significantly to the symptoms of dementia. The second is the issue of whether scopolamine administration provides an adequate model of the cholinergic system 
dysfunction of SDAT. Both the differences between the mechanism of action of scopolamine and the pathophysiology of SDAT, and the inability of scopolamine to mimic many of the non-mnestic impairments of SDAT, raise serious questions about the scopolamine model. The principal evidence that provides support for the scopolamine model of SDAT is the similarity between the memory impairments induced by scopolamine and the memory impairments associated with SDAT (Broks et al., 1988; Caine et al., 1981; Kopelman and Corn, 1988; Obonsawin et al., 1996; Rusted and Warburton, 1988). These results imply that the scopolamine model of SDAT is a valid one, and that cholinergic dysfunction underlies some of the memory problems in SDAT. However, the memory difficulties in SDAT may be explained more parsimoniously by the progressive deterioration of other structures of the brain associated with memory, like the hippocampus. More recently, Cummings and Kaufer (1996) have suggested that cholinergic dysfunction may be the basis for some of the neuropsychiatric symptoms associated with SDAT, but there has been little research on this issue. The validity of the scopolamine model of dementia remains to be determined, but the results of the present study do not provide support for the hypothesis that cholinergic dysfunction is the basis for the non-mnestic cognitive impairments in SDAT.

\section{ACKNOWLEDGEMENTS}

The authors thank the Mental Health Foundation for their generous financial support of this research project. The authors also thank Professor G. Ashcroft, Dr Z. Erskine, Dr P. Olley, Dr E. R. Alexander, Dr A. Haddow and Dr W. Cheyne for their valuable contributions to the study. We are particularly grateful to the participants who volunteered their time, to Ms C. Milne, and the Aberdeen Branch of Alzheimer's Scotland.

\section{REFERENCES}

Aarsland, D., Larsen, J. P., Reinvang, I. and Aarsland, A. M. (1994). Effects of cholinergic blockade on language in healthy young women. Implications for the cholinergic hypothesis in dementia of the Alzheimer type. Brain, 117, 1377-1384.

Bartus, R. T., Dean III, R. L., Beer, B. and Lippa, A. S. (1982). The cholinergic hypothesis of geriatric memory dysfunction. Science, 217, 408-417.
Beatty, W. W., Butter, N. and Janowsky, D. S. (1986). Patterns of memory failure after scopolamine treatment: implications for cholinergic hypotheses of dementia. Behavioral and Neural Biology, 45, 196-211.

Benton, A. L. and Hamsher, K. (1976). Multilingual Aphasia Examination. University of Iowa, Iowa City.

Benton, A. L. and Hamsher, K. (1978). Manual for Multilingual Aphasia Examination. University of Iowa, Iowa City.

Benton, A. L., Hamsher, K., Varney, N. R. and Spreen, O. (1983). Judgment of Line Orientation, Form H. In: Contributions to Neuropsychological Assessment, Benton, A. L., Hamsher, K. de S., Varney, N. R. and Spreen, O. (Eds), Oxford University Press, New York.

Bondi, M. W., Monsch, A. U., Butters, N., Salmon, D. P. and Paulsen, J. S. (1993). Utility of a modified version of the Wisconsin Card Sorting Test in the detection of dementia of the Alzheimer type. The Clinical Neuropsychologist, 7, 161-170.

Bowen, D. M. (1984). Cellular ageing: selective vulnerability of cholinergic neurons in human brain. Monographs in Developmental Biology, 17, 42-59.

Brinkman, S. D. and Braun, P. (1984). Classification of dementia patients by a WAIS profile related to central cholinergic deficiencies. Journal of Clinical Neuropsychology, 6, 393-400.

Broks, P., Preston, G. C., Traub, M., Poppleton, P., Ward, C. and Stahl, S. M. (1988). Modelling dementia: effects of scopolamine on memory and attention. Neuropsychologia, 26, 685-700.

Brown, J. H. (1990). Atropine, scopolamine and related antimuscarnic drugs. In: The Pharmacological Basis of Therapeutics, Gilman, A. G., Rall, T. W., Nies, A. S. and Taylor, P. (Eds), Pergamon Press, New York, pp. $150-165$.

Caine, E. D., Weingartner, H., Ludlow, C. L., Cudahy, E. A. and Wehry, S. (1981). Qualitative analysis of scopolamine-induced amnesia. Psychopharmacology, 74, 74-80.

Christensen, H., Maltby, N., Jorm, A. F., Creasey, H. and Broe, G. A. (1992). Cholinergic 'blockade' as a model of the cognitive deficits in Alzheimer's disease. Brain, 115, 1681-1699.

Coyle, J. T., Price, D. L. and DeLong, M. R. (1983). Alzheimer's disease: a disorder of cortical cholinergic innervation. Science, 219, 1184-1190.

Crawford, J. R., Besson, J. A. O. and Ebmeier, K. P. (1990). Dementia: the role of neurotransmitter deficits. In: Principles and Practice of Biological Psychiatry, Volume 2, Dinan, T. (Ed.), Clinical Neuroscience Publishers, London, pp. 105-133.

Crawford, J. R., Besson, J. A. O., Evans, N. T. S., Roeda, D., Kulkarni, V., Parker, D. M., Ebmeier, K. P., Allan, K. M. and Mallard, J. R. (1992). Cerebral blood flow in Alzheimer's disease imaged by positron emission tomography: the effects of physostigmine infusion. In: Geriatric Psychiatry and the New Technologies, Kalousek, M. E. (Ed.), Jansen, Neuss, pp. 109-138. 
Cullen, K. M., Halliday, G. M., Double, K. L., Brooks, W. S., Creasey, H. and Broe, G. A. (1997): Cell loss in the nucleus basalis is related to regional cortical atrophy in Alzheimer's disease. Neuroscience, 78, 641-652.

Cummings, J. L. and Kaufer, D. (1996). Neuropsychiatric aspects of Alzheimer's disease: the cholinergic hypothesis revisited. Neurology, 47, 876-883.

Curran, H. V., Schifano, F. and Lader, M. (1991). Models of memory dysfunction? A comparison of the effects of scopolamine and lorazepam on memory, psychomotor performance and mood. Psychopharmacology, 103, 83-90.

Davies, P. (1978). Loss of choline acetyltransferase activity in normal aging and in senile dementia. Advances in Experimental Medicine and Biology, 113, 251-256.

Drachman, D. A. and Leavitt, J. (1972). Memory impairment in the aged: storage versus retrieval deficit. Journal of Experimental Psychology, 93, 302-308.

Drachman, D. A. and Leavitt, J. (1974). Human memory and the cholinergic system. A relationship to aging? Archives of Neurology, 30, 113-121.

Dunne, M. P. (1990). Scopolamine and sustained retrieval from semantic memory. Journal of Psychopharmacology, 4, 13-18.

Dunne, M. P. (1993). Further evidence that scopolamine can improve verbal fluency. Journal of Psychopharmacology, 7, 159-163.

Dunnet, S. (1991). Cholinergic grafts, memory and ageing. Trends in Neuroscience, 14, 371-376.

Eagger, S. A., Levy, R. and Sahakian, B. J. (1991). Tacrine in Alzheimer's disease. Lancet, 337, 989-992.

Emery, V. O. B. (1985). Language and aging. Experimental Aging Research Monograph Series, 11, 1-63.

Eslinger, P. J. and Benton, A. L. (1983). Visuoperceptual performances in aging and dementia: clinical and theoretical implications. Journal of Clinical Neuropsychology, 5, 213-220.

Eslinger, P. J., Damasio, A. R., Benton, A. L. and van Allen, M. (1985). Neuropsychological detection of abnormal mental decline in older persons. Journal of American Medical Association, 253, 670-674.

Faber-Langendoen, K., Morris, J. C., Knesevich, J. W., LaBarge, E., Miller, J. P. and Berg, L. (1988). Aphasia in senile dementia of the Alzheimer type. Annals of Neurology, 23, 365-370.

Farlow, M., Gracon, S. I., Hershey, L. A., Lewis, K. W., Sadowsky, C. H. and Dolan-Ureno, J. (1992). A controlled trial of tacrine in Alzheimer's disease. Journal of the American Medical Association, 268, 2523-2529.

Filley, C. M., Kobayashi, J. and Heaton, R. K. (1987). Wechsler Intelligence Scales profiles, the cholinergic system, and Alzheimer's disease. Journal of Clinical and Experimental Neuropsychology, 9, 180-186.

Flicker, C., Serby, M. and Ferris, S. H. (1990). Scopolamine effects on memory, language, visuospatial praxis and psychomotor speed. Psychopharmacology, 100, 243-250.
Flicker, C., Ferris, S. H. and Serby, M. (1992). Hypersensitivity to scopolamine in the elderly. Psychopharmacology, 107, 437-441.

Folstein, M. F., Folstein, S. E. and McHugh, P. R. (1975). Mini-Mental State: a practical method for grading the cognitive state of patients for the clinician. Journal of Psychiatric Research, 12, 189-198.

Freeman, S. E. and Dawson, R. M. (1991). Tacrine: a pharmacological review. Progress in Neurobiology, 36, 257-277.

Freund, G. (1980). Cholinergic receptor loss in brains of aging mice. Life Sciences, 26, 371-375.

Fuld, P. A. (1984). Test profile of cholinergic dysfunction and of Alzheimer-type dementia. Journal of Clinical Neuropsychology, 6, 380-392.

Gallagher, M. and Colombo, P. J. (1995). Ageing: the cholinergic hypothesis of cognitive decline. Current Opinion in Neurobiology, 5, 161-168.

Gfeller, J. D. and Rankin, E. J. (1991). The WAIS-R profile as a cognitive marker of Alzheimer's disease: A misguided venture? Journal of Clinical and Experimental Neuropsychology, 13, 629-636.

Ghoneim, M. M. and Mewaldt, S. P. (1977). Studies on human memory: the interactions of diazepam, scopolamine and physostigmine. Psychopharmacology, 52, $1-6$.

Gibson, G. E. and Peterson, C. (1981). Aging decreases oxidative metabolism and the release and synthesis of acetylcholine. Journal of Neurochemistry, 37, 978-984.

Goldman, R. S., Axelrod, B. N., Giordani, B. J., Foster, N. and Berent, S. (1992). Longitudinal sensitivity of the Fuld cholinergic profile to Alzheimer's disease. Journal of Clinical and Experimental Neuropsychology, 14, 566-574.

Goodglass, H. and Kaplan, E. (1972). An Assessment of Aphasia and Related Disorders. Lea and Fibiger, Philadelphia.

Gottfries, G. C. (1990). Neurochemical aspects on aging and disease with cognitive impairment. Journal of Neuroscience Research, 27, 541-547.

Hart, R. P., Kwentus, J. A., Wade, J. B. and Taylor, J. R. (1988). Modified Wisconsin Card Sorting Test in elderly normal, depressed and demented patients. The Clinical Neuropsychologist, 2, 49-56.

Heinrichs, R. W. and Celinski, M. J. (1987). Frequency of occurrence of a WAIS dementia profile in male head trauma patients. Journal of Clinical and Experimental Neuropsychology, 9, 187-190.

Kasa, P., Rakonczay, Z. and Gulya, K. (1997). The cholinergic system in Alzheimer's disease. Progress in Neurobiology, 52, 511-535.

Kirkby, D. L., Jones, D. N. C., Barnes, J. C. and Higgins, G. A. (1996). Effects of anticholinesterase drugs tacrine and E2020, the 5HT3 antagonist ondansetron, and the $\mathrm{H} 3$ antagonist thioperamide, in models of cognition and cholinergic function. Behavioural Pharmacology, 7, 513-525. 
Kopelman, M. D. and Corn, T. H. (1988). Cholinergic 'blockade' as a model for cholinergic depletion. A comparison of the memory deficits with those of Alzheimer-type dementia and the alcoholic Korsakoff syndrome. Brain, 111, 1079-1100.

Lines, C. R., Preston, G. C., Broks, P. and Dawson, C. E. (1991). The effects of scopolamine on retrieval from semantic memory. Journal of Psychopharmacology, 5, 234-237.

Massman, P. J. and Bigler, E. D. (1993). A quantitative review of the diagnostic utility of the WAIS-R Fuld profile. Archives of Clinical Neuropsychology, 8, 417-428.

McGeer, E. G. and McGeer, P. L. (1981). Cholinergic mechanisms in central disorders. In: Neuropharmacology of Central Nervous System and Behavioral Disorders, Palmer, G. C. (Ed.), Academic Press, New York.

Mesulam, M.-M. (1991). Behavioral neuroanatomy of cholinergic innervation in the primate cerebral cortex. In: Activation to Acquisition: Functional Aspects of the Basal Forebrain Cholinergic System, Richardson, R. T. (Ed.), Birkhäuser, Boston, pp. 73-85.

Mesulam, M.-M., Mufson, E. J. and Rogers, J. (1987). Age-related shrinkage of cortically projecting cholinergic neurons: a selective effect. Annals of Neurology, 22, 31-36.

Mewaldt, S. P. and Ghoneim, M. M. (1979). The effects and interactions of scopolamine, physostigmine and methamphetamine on human memory. Pharmacology, Biochemistry and Behavior, 10, 205-210.

Meyer, E. M., St Onge, E. and Crews, F. T. (1984). Effects of aging on rat cortical presynaptic cholinergic processes. Neurobiology of Aging, 5, 315-317.

Miller, E. (1984). Verbal fluency as a function of a measure of verbal intelligence and in relation to different types of cerebral pathology. British Journal of Clinical Psychology, 23, 53-57.

Molchan, S. E., Martinez, R. A., Hill, J. L., Weingartner, H. J., Thompson, K., Bitiello, B. and Sunderland, T. (1992). Increased cognitive sensitivity to scopolamine with age and a perspective on the scopolamine model. Brain Research Reviews, 17, 215-226.

Murray, T. K. and Cross, A. J. (1991). Reversal by tetrahydroaminoacridine of scopolamine-induced memory and performance deficits in rats. Psychopharmacology, 105, 134-136.

Nelson, H. E. (1976). A modified card sorting test sensitive to frontal lobe defects. Cortex, 12, 313-324.

Nelson, H. E. (1982). National Adult Reading Test. Test Manual. NFER Nelson, Windsor.

Obonsawin, M. C., Goddard, C., Crawford, J. R., Al-Mousawi, A., Evans, N. T. S., Roeda, D., MacLennan, F., Parker, D. M. and Besson, J. A. O. (1996). The effects of scopolamine on the recall of repeated words: a preliminary investigation. Human Psychopharmacology, 11, 25-32.
Ott, B. R., Ellias, S. A. and Lannon, M. C. (1995). Quantitative assessment of movement in Alzheimer's disease. Journal of Geriatric Psychiatry \& Neurology, 8, 71-75.

Parker, D. M. and Crawford, J. R. (1992). Assessment of frontal lobe dysfunction. In: A Handbook of Neuropsychological Assessment, Crawford, J. R., Parker, D. M. and McKinlay, W. W. (Eds), Lawrence Erlbaum Associates, Hove, pp. 267-291.

Raven, J. C. (1958). Standard Progressive Matrices. H. K. Lewis \& Co., London.

Riekkinen, Jr, P., Jakala, P., Sirvio, J., Koivisto, E., Miettinen, R. and Riekkinen, P. (1991). The effects of THA on scopolamine and nucleus basalis lesioninduced EEG slowing. Brain Research Bulletin, 26, 633-637

Rosen, W. G. (1980). Verbal fluency in aging and dementia. Journal of Clinical Neuropsychology, 2, 135-146.

Rusted, J. M. and Warburton, D. M. (1988). The effects of scopolamine on working memory in healthy young volunteers. Psychopharmacology, 96, 145-152.

Ryan, J. J. and Paolo, A. M. (1989). Frequency of occurrence of a WAIS dementia pattern in schizophrenia and bipolar affective disorder. The Clinical Neuropsychologist, 3, 45-48.

Safer, D. J. and Allen, R. P. (1971). The central effects of scopolamine in man. Biological Psychiatry, 3, 347-355.

Sahakian, B. J., Owen, A. M., Morant, N. J., Eagger, S. A., Boddington, S., Crayton, L., Crockford, H. E., Crooks, M., Hill, K. and Levy, R. (1993). Further analysis of the cognitive effects of tetrahydroaminoacridine (THA) in Alzheimer's disease: assessment of attentional and mnemonic function using CANTAB. Psychopharmacology, 110, 395-401.

Satz, P., van Gorp, W., Soper, H. V. and Mitrushina, M. (1987). WAIS-R marker for dementia of the Alzheimer's type? An empirical and statistical induction test. Journal of Clinical and Experimental Neuropsychology, 9, 767-774.

Satz, P., D'Elia, L., van Gorp, W., Hynd, G. W., Daniel, M. H. and Conno, R. (1990). A WAIS-R marker for accelerated aging and dementia, Alzheimer's type?: Base rates of the Fuld formula in the WAIS-R standardization sample. Journal of Clinical and Experimental Neuropsychology, 12, 759-765.

Ska, B., Poissant, A. and Joanette, Y. (1990). Line orientation judgment in normal elderly and participants with dementia of Alzheimer's type. Journal of Clinical and Experimental Neuropsychology, 12, 695-702.

Spellacy, F. J. and Spreen, O. (1969). A short form of the token test. Cortex, 5, 390-397.

Sunderland, T., Tariot, P. N., Cohen, R. M., Weingartner, H., Mueller, E. A. and Murphy, D. L. (1987). Anticholinergic sensitivity in patients with dementia of the Alzheimer type and age-matched controls: a dose response study. Archives of General Psychiatry, 44, 418-426. 
Thompson, I. M. (1987). Language in dementia. International Journal of Geriatric Psychiatry, 2, 145-161.

Tsukada, H., Kakiuchi, T., Ando, I. and Ouchi, Y. (1997). Functional activation of cerebral blood flow abolished by scopolamine is reversed by cognitive enhancers associated with cholinesterase inhibition: a positron emission tomography study in unanesthetized monkeys. Journal of Pharmacology \& Experimental Therapeutics, 281, 1408-1414.

Tuokko, H. and Crockett, D. (1987). Central cholinergic deficiency WAIS profiles in a non-demented aged sample. Journal of Clinical and Experimental Neuropsychology, 9, 225-227. van Gorp, W. G., Tulin, S. J., Evans, G. and Satz, P. (1990). Incidence of the WAIS-R Fuld profile in HIV-1 infection. Journal of Clinical and Experimental Neuropsychology, 12, 807-811.

Wechsler, D. (1981). Wechsler Adult Intelligence Scales - Revised, Manual. The Psychological Corporation, New York.

Zemishlany, Z. and Thorne, A. E. (1991). Anticholinergic challenge and cognitive functions: a comparison between young and elderly normal participants. Israeli Journal of Psychiatry and Related Sciences, 28, 32-41. 